\title{
Effects of Alcohol on the Endocrine System
}

\author{
Nadia Rachdaoui ${ }^{1}$ and Dipak K. Sarkar ${ }^{2}$ \\ ${ }^{1}$ Nadia Rachdaoui, Ph.D., Rutgers Endocrine Research Program. Department of Animal Sciences \\ Rutgers University, 67 Poultry Farm Lane, New Brunswick, NJ 08901, \\ nadia.rachdaoui@gmail.com \\ ${ }^{2}$ Dipak K. Sarkar, Ph.D., D. Phil., Rutgers Endocrine Research Program. Department of Animal \\ Sciences, Rutgers University, 67 Poultry Farm Lane, New Brunswick, NJ 08901, \\ sarkar@aesop.rutgers.edu
}

\begin{abstract}
Synopsis-The endocrine system ensures a proper communication between various organs of the body to maintain a constant internal environment. The endocrine system also plays an essential role in enabling the body to respond and appropriately cope with changes in the internal or external environments, such as respond to stress and injury. These functions of the endocrine system to maintain body homeostasis are aided by its communication with the nervous system, immune system and body's circadian mechanism. Chronic consumption of a large amount of alcohol disrupts the communication between nervous, endocrine and immune system and causes hormonal disturbances that lead to profound and serious consequences at physiological and behavioral levels. These alcohol-induced hormonal dysregulations affect the entire body and can result in various disorders such as stress abnormalities, reproductive deficits, body growth defect, thyroid problems, immune dysfunction, cancers, bone disease and psychological and behavioral disorders. This review summarizes the findings from human and animal studies that provide consistent evidence on the various effects of alcohol abuse on the endocrine system.
\end{abstract}

\section{Keywords}

Alcoholism; endocrine disorders; circadian dysfunction and immune abnormalities

\section{Introduction}

Alcohol consumption is one of the most serious substance abuse disorders worldwide. Alcohol-related deaths, diseases and disabilities are much higher in men than women and are highest in developed countries, where they range from $8 \%-18 \%$ for males and $2 \%-4 \%$ for females. According to the National Institute of Alcohol Abuse and Alcoholism, each year, approximately 80,000 people die from alcohol-related causes, making it the third leading cause of death in the United States. Approximately 14 million of Americans (7.4\%)

(C) 2013 Elsevier Inc. All rights reserved.

Corresponding author: Dipak K. Sarkar, Ph.D., D. Phil., Rutgers Endocrine Research Program. Department of Animal Sciences, Rutgers University, 67 Poultry Farm Lane, New Brunswick, NJ 08901, sarkar@aesop.rutgers.edu; Phone: 848-932-1529; Fax: 732-932-4134.

Publisher's Disclaimer: This is a PDF file of an unedited manuscript that has been accepted for publication. As a service to our customers we are providing this early version of the manuscript. The manuscript will undergo copyediting, typesetting, and review of the resulting proof before it is published in its final citable form. Please note that during the production process errors may be discovered which could affect the content, and all legal disclaimers that apply to the journal pertain.

Disclosures:

Conflict of interest: We have nothing to disclose. 
have an alcohol use disorder that is classified as either alcoholism (alcohol dependency) or alcohol abuse ${ }^{1}$. There is considerable evidence, from human genome-wide association studies of individuals with family history of alcoholism and twin studies that several susceptibility genes are linked to the vulnerability and risk of developing alcohol-related disorders. Heritability of alcohol abuse, from twin studies, was estimated to range from 50 to $60 \% 2 ; 3$. However, alcoholism is a multi-factorial and polygenic disorder in which complex gene-to-gene and gene-to-environment interactions occur resulting in a variety of addiction phenotypes. Environmental factors play an equally important role in the development of alcohol-related disorders, i.e. stressful life events have been shown to influence alcohol drinking and relapse behaviors ${ }^{4}$.

Excessive alcohol drinking has been recognized as having several adverse health consequences. Heavy alcohol drinking increases the risk of cardiovascular and liver disease, metabolic disturbances, nutritional deficiencies, cancers (i.e. mouth, stomach, colon, liver and breast cancer), neurobiological disorders and fetal abnormalities ${ }^{5}$. In contrast to heavy alcohol use, light to moderate drinking, especially of alcoholic beverages rich in polyphenols such as red wine, was reported to lower the risk of coronary heart disease ${ }^{6}$, stroke $^{7}$ and osteoporosis ${ }^{8}$. In this article we will discuss some of the literature surrounding studies done in humans and animal models regarding the effects of both acute and chronic alcohol consumption on one of the body's most important systems, the endocrine system.

\section{The endocrine system}

Along with the nervous system, the endocrine system ensures a proper communication between various organs of the body to maintain a constant internal environment, also called homeostasis. The nervous system allows rapid transmission of information between different body regions, whereas, the endocrine system, which is a complex system of glands that produce and secrete hormones directly into the blood circulation, have longer lasting actions. Almost every organ and cell in the body is affected by the endocrine system. The endocrine system controls metabolism and energy levels, electrolyte balance, growth and development and reproduction. The endocrine system also plays an essential role in enabling the body to respond and appropriately cope with changes in the internal or external environments, such as changes in the body's temperature or in the electrolyte composition of the body's fluids as well as respond to stress and injury. Substance abuse, such as chronic alcohol consumption was shown to have serious adverse effects on the different components of the endocrine system ${ }^{9}$. Alcohol's effects induce hormonal disturbances that lead to profound and serious consequences at physiological and behavioral levels. These alcoholinduced hormonal dysregulations affect the entire body and can result in various disorders such as cardiovascular diseases, reproductive deficits, immune dysfunction, certain cancers, bone disease and psychological and behavioral disorders.

The goal in this review is to discuss the effects of both acute and chronic alcohol exposures on the different components of the endocrine system. We will summarize the findings from human and animal studies that provide consistent evidence on the various effects of alcohol abuse on the endocrine system and on how the latter might have a role in the initiation, the development and the maintenance of alcohol drinking disorders and relapse. We will first discuss the impact of alcohol on the primary hormonal center of the endocrine system, the hypothalamic-pituitary axis and review how its different components, the adrenal axis (Hypothalamic Pituitary Adrenal axis; HPA axis), the gonadal axis (Hypothalamic Pituitary Gonadal axis; HPG axis) and the thyroid axis (Hypothalamic Pituitary Thyroid axis; HPT axis) are affected by alcohol consumption. We will also review the role that the HPA axis plays in the alcohol seeking behavior and dependence and discuss the effects of alcohol consumption on the activity of the HPA axis. Second, we will review the recent literature on the effects of alcohol on body growth, circadian mechanism and the pancreas. Lastly, and 
since it is currently well documented that there is an overlap between the endocrine and the immune systems, we will discuss how dysregulation in the hypothalamic-pituitary axis can negatively impact the body's immune response.

\section{Alcohol and the hypothalamic-pituitary-adrenal axis}

The HPA axis, also called the stress axis, is a major component of the neuroendocrine system that controls the body's response to environmental stressors (psychological, physical or infectious) and regulates many of the body's physiological processes such as metabolism, reproduction, growth, mood and emotions and the immune function. In response to any type of stress, release of corticotropin-releasing hormone (CRH) and increased peripheral glucocorticoid levels initiate a cascade of biological responses that help counteract the altered homeostatic state. Parvocellular neurons in the paraventricular nucleus (PVN) of the hypothalamus synthesize and secrete $\mathrm{CRH}$ into the hypothalamic-pituitary portal network that connects the hypothalamus and the anterior pituitary. At the anterior pituitary, $\mathrm{CRH}$ stimulates the synthesis and secretion of a proopiomelanocortin (POMC)-derived peptide called adrenocorticotropic hormone (ACTH) from corticotropic cells. ACTH is then transported through the blood circulation to the adrenal glands where it acts on the zona fasciculata cells in the adrenal cortex to stimulate the production of glucocorticoids, mainly cortisol in humans and corticosterone in rodents. Glucocorticoids then, through a negative feedback loop, act on the hypothalamus, hippocampus and the pituitary to decrease $\mathrm{CRH}$ and ACTH production. This regulation is done by a feedback system via glucocorticoid receptors (GR) in the PVN, and mineralocorticoid receptors (MR) and GR in the hippocampus. Glucocorticoid receptors inhibit HPA activity; because at basal levels of cortisol, the MR are occupied while GR are mostly unoccupied. However, when there are elevated levels of plasma cortisol, like during a period of stress, there is an increased occupation of GR. It is the increased occupation of GR that triggers the negative feedback. The glucocorticoids released by the adrenal cortex interact with the GR in the pituitary, hypothalamus and hippocampus; so any over-activity results in feedback causing a reduction in circulating $\mathrm{CRH}$, thereby 'switching off' the stress response. In addition to their main function in restoring homeostasis following exposure to stress, glucocorticoids influence carbohydrate, lipid and nucleic acid metabolism, bone and calcium metabolism, growth and development, it also have immuno-supressive and anti-inflammatory effects ${ }^{10}$.

Perturbations of the HPA-axis may, therefore, have serious long-term health consequences.

The other main physiological aspect of the stress response is the autonomic nervous system (ANS). The ANS has the capacity to trigger two opposing responses- the 'flight or flight' of the sympathetic nervous system or the 'tend and mend' of the parasympathic nervous system. The release of ACTH from the pituitary signals not only to induce the synthesis of glucocorticoids, but also the release of catecholamines from the adrenal glands.

Catecholamines such as epinephrine and norepinephrine trigger the activation of the sympathetic nervous system (SNS) that results in the familiar feeling of decreased saliva, increased perspiration and heart rate. The SNS is the first line of defense against the stressor, traditionally allowing escape from the immediate threat. However, such a response cannot be physiologically maintained for long periods of time.

As part of the SNS response to stress, the opioid peptide $\beta$-endorphin (BEP) is synthesized by POMC and is implicated in the behavioral as well as the biological response associated with stress stimuli. The most well studied effect of BEP is its ability to modulate pain, but the peptide has also been implicated in the central regulation of ACTH and hypothalamic $\mathrm{CRH}$. Indeed, BEP has been shown to play a critical role in bringing the stress response to a state of homoeostasis. In response to stress, the secretion of $\mathrm{CRH}$ and catecholamines stimulate the synthesis of BEP and other POMC-derived peptides from the hypothalamus, which in turn inhibit the activity of the HPA axis. Central BEP binds to $\delta$ and $\mu$ opioid 
receptors and modulates the ANS via neurons within the PVN. BEP produced from pituitary POMC that circulates in the periphery is primarily regulated by CRH and AVP and has less impact on ANS function ${ }^{11}$.

Considerable evidence, from human and animal studies, has shown that alcohol administration affects the HPA-axis activity. An acute exposure to alcohol activates the HPA stress axis leading to a dose-related increase in circulating ACTH and glucocorticoids. In rats, an acute administration of ethanol increases plasma ACTH and corticosterone levels, with females showing a higher response then males ${ }^{12}$. These ethanol effects are primarily mediated through an enhanced release of CRH from the hypothalamus. Neutralization of circulating CRH with antibodies interrupts the stimulatory effects of ethanol on ACTH and corticosterone secretion ${ }^{13}$. Lesions of the PVN attenuate, but do not abolish the stimulatory effects of ethanol on ACTH release, suggesting that extra PVN regions, and/or other ACTH secretagogues, such as vasopressin, mediate the ethanol-stimulation of ACTH release.

Neutralization of endogenous vasopressin, using antibodies, decreased the ethanol-induced ACTH secretion in both sham-operated and PVN-sectioned rats, indicating that vasopressin from outside the PVN partially mediates the pituitary-adrenocortical response to ethanol ${ }^{14}$.

In humans, several studies have also reported the stimulatory effect of alcohol on the HPAaxis. In an early study, Jenkins and Connolly ${ }^{15}$ showed that plasma cortisol levels significantly increased in healthy subjects at alcohol doses exceeding $100 \mathrm{mg} / 100 \mathrm{ml}$. In a recent study by Thayer and colleagues ${ }^{16}$, it was shown that healthy men who were selfreported alcohol consumption, had higher levels of excreted cortisol in urine. These authors also reported that in heavy drinkers, the inhibitory control of the HPA axis was impaired. Richardson and colleagues ${ }^{17}$, using an operant self-administration animal model of alcohol dependence, showed that the HPA responses to several weeks of daily 30-min selfadministration of alcohol were higher in 'low-responding' non-dependent animals $(<0.2$ $\mathrm{mg} / \mathrm{kg} / \mathrm{session})$, intermediate in non-dependent animals $(\sim 0.4 \mathrm{mg} / \mathrm{kg} / \mathrm{session})$, and most blunted in dependent animals $(\sim 1.0 \mathrm{mg} / \mathrm{kg} / \mathrm{session})$. This and a number of other studies have all shown that basal ACTH and corticosterone levels are attenuated in response to chronic exposure to alcohol.

A decrease in CRH mRNA expression in the $\mathrm{PVN}^{18}$ and a reduced responsiveness of the pituitary to $\mathrm{CRH}^{19}$ were also observed. Low CRH levels were associated with more intense craving and increased probability of relapse after acute abstinence suggesting that the CRH system plays an important role in the control of long-term alcohol drinking and dependence. In CRH knock-out mice ethanol intake was doubled and the behavioral response to ethanol was diminished ${ }^{20}$. In rhesus macaques, which had a single nucleotide polymorphism in the promoter region of CRH (-248C--> T) that confers increased stress reactivity, it was shown that release of $\mathrm{ACTH}$, cortisol and suppression of environmental exploration (a behavioral response to social separation stress) were higher in those with the $\mathrm{T}$ allele ${ }^{21}$. These animals consumed more alcohol in a limited-access paradigm, suggesting that the $\mathrm{CRH}$ promoter variation which conferred increased stress responsivity also increased the risk for alcohol dependence. It has also been demonstrated that in mice lacking a functional CRH1 receptor, repeated stress leads to enhanced and progressively increasing ethanol consumption that seems to persist throughout their life $\mathrm{e}^{22}$. This effect was associated with enhanced protein levels of NR2B subunit of the NMDA receptor of the glutamargic system also known to be involved in addiction behavior ${ }^{23}$. As reported by Koob and colleagues ${ }^{24}$, disruptions in the CRH system develop over time and are worsened by prolonged exposure to excessive alcohol drinking. This phenomenon is seen only in rat strains that are prone to selfadminister alcohol; in non-dependent rats, the CRH system does not significantly modulate ethanol consumption ${ }^{25,26}$. 
A role for ACTH and corticosteroids has also been documented in alcohol consumption behavior. Injections of ACTH analogues to rats exposed to free-choice ethanol consumption (10\% ethanol) led to a reduction in ethanol consumption ${ }^{27}$. In another study by Fahlke and colleagues $^{28}$, male rats of alcohol-preferring (AA) and alcohol-avoiding (ANA) strains were adrenalectomized then given access to $10 \%(\mathrm{v} / \mathrm{v})$ ethanol or water for 2 weeks. This study showed that adrenalectomy results in decreased ethanol consumption in AA rats compared to sham-operated AA controls and injection with corticosterone restores the ethanol consumption. In contrast, no alterations in ethanol intake after adrenalectomy and following corticosterone injection were observed in the ANA rats. These data suggest that corticosterone stimulates ethanol consumption in animals with high preference for alcohol ${ }^{28}$. In a subsequent study the same authors found that intracerebroventricular infusions of corticosterone restore ethanol intake in adrenalectomized animals to levels similar to shamoperated controls ${ }^{29}$. These data suggest that differences in the activity of the HPA axis may help determine whether certain individuals are at high risk for developing alcohol-related disorders and alcoholism.

A relationship between the endogenous opioid system, the HPA axis and reward has been proposed $^{30}$. BEP neurons in the arcuate nucleus of the hypothalamus both inhibit CRH release in the PVN of the hypothalamus ${ }^{31}$ and simultaneously stimulate dopamine release in the nucleus accumbens ${ }^{32}$. Because the opioids are involved in regulating both of these systems, it is proposed that a deficit in opioid neurotransmission may cause a simultaneous derangement of both physiological processes. In recent years, a body of research has accumulated that provides evidence of deranged HPA axis function in drinking alcoholics ${ }^{33}$ in acute withdrawal and more prolonged abstinence ${ }^{17}$, as well as in nondependent individuals with a family history of alcoholism ${ }^{34}$. Also, glucocorticoids, which are released during stress and following ethanol-induced activation of the HPA axis, modulate the activities of the opioidergic, CRH, and mesolimbic dopaminergic systems ${ }^{35}$ and have been shown to interact with the rewarding properties of alcohol abuse ${ }^{36}$. It is beleived that diminished opioid activity, which is either the result of alcoholism or genetically linked to the risk of alcoholism, could induce hypercortisolemia, alter mesolimbic DA production, and lead to abnormal ethanol reinforcement ${ }^{32,33}$.

\section{Alcohol and the hypothalamic-pituitary-gonadal axis}

Alcohol abuse and alcoholism are associated with disorders of reproductive function in both men and women. The hypothalamic-pituitary-gonadal axis (HPG) and its hormones are essential for proper functioning of reproductive system. In alcohol abusers, the HPG dysfunction was shown to be associated with a decrease in libido, infertility and gonadal atrophy. Several studies have clearly documented that alcohol has deleterious effects on all three components of the HPG axis, the hypothalamus, pituitary, and gonads. We will review some of these studies on the acute and chronic effects of alcohol on male and female reproductive systems.

\subsection{Overview of male and female hypothalamic-pituitary-gonadal axis-The}

hypothalamus in a pulsatile way produces and secretes the hormone called luteinizing hormone-releasing hormone (LHRH), also called gonadotropin-releasing hormone (GnRH), into the hypothalamic-pituitary portal network ${ }^{37}$. At the anterior pituitary, LHRH binds to specific receptors on gonadotroph cells and stimulates a cascade of events that lead to production and secretion of two important gonadotropin hormones, follicle-stimulating hormone (FSH) and luteinizing hormone (LH) into the general circulation. In the ovary, during the follicular phase of each reproductive cycle ( 28 days in human cycle), FSH stimulates the development of a dominant follicle which, as it matures, produces and secretes increasing amounts of the estrogen called estradiol. Both FSH and LH stimulate 
estradiol secretion and this rise in estradiol is responsible for the LH and FSH surge seen in midcycle. LH then stimulates ovulation and the development of the corpus luteum during the luteal phase which then produces and secretes progesterone, an important hormone in the preparation of the uterine wall for the fertilized egg and for the maintenance of the pregnancy. In the testis, LH stimulates testosterone secretion while FSH controls the initiation and maintenance of spermatogenesis. In addition, testosterone, estrogen and progesterone, control their own production through a feedback loop mechanism and can act on the hypothalamus and the pituitary to either inhibit or stimulate the release of LHRH, LH and $\mathrm{FSH}^{38}$.

Although, sex hormones are essential to reproductive processes, they can also act on other organs in the body and trigger numerous physiological processes. For example, estrogen, progesterone and testosterone were shown to play an important role in maintaining normal bone mass 39,40 . Estrogen is a vasodilator agent that can induce vascular relaxation ${ }^{41}$ and was shown to reduce the risk of atherosclerosis and therefore cardiovascular disease in menopausal women by decreasing circulating low-density lipoproteins (LDL) and inflammatory processes in the vasculature ${ }^{42}$. Testosterone was also shown to impact muscle mass and adiposity in adult men ${ }^{43}$ and to affect emotional and cognitive behavior ${ }^{44}$. Dysregulation of the hypothalamic-pituitary-gonadal axis, therefore, can lead not only to reproductive dysfunction but also to other serious health problems such as mood and memory disorders, osteoporosis and muscle atrophy.

\subsection{Alcohol and hypothalamic-pituitary-gonadal axis in puberty-Normal}

initiation and progression of puberty is under the control and is mediated by central inputs which stimulate the pulsatile diurnal secretion of LHRH into the hypothalamic-pituitary portal system. LHRH then stimulates the pituitary gonadotropin secretion and subsequent ovarian maturation $^{45}$. This LHRH surge, which is normally inhibited during childhood through hypothalamic inhibitory inputs such as gamma aminobutyric acid and opioid peptides is triggered at puberty by stimulatory agents such as insulin-like growth factor-1 (IGF-1), norepinephrine, leptin, transforming growth factor (TGF)- $a$ and the kisspeptins ${ }^{46-48}$.

Little research has been done on the impact of alcohol consumption during puberty in humans. However, numerous studies documented decrease in estrogen levels adolescent girls and that this decrease was sustained for prolonged periods after consumption of a moderate amount of alcohol ${ }^{49}$. Alcohol abuse was also shown to induce alterations in puberty-related hormones in adolescent boys evidenced by significant reductions in testosterone, LH and FSH levels ${ }^{50}$. In the last decade or so, however, the use of animal models such as rodents and monkeys helped in understanding and identifying some of the mechanisms by which alcohol abuse affects puberty-related processes. In early studies on female rats, Bo and colleagues ${ }^{51}$ reported that puberty, measured by vaginal opening, was markedly delayed in prepubertal female rats administered alcohol. Naltrexone which is a blocker of the opioid receptors completely prevented the alcohol-induced delay in vaginal opening $^{52}$, which suggests that alcohol-induced pubertal delay might in part be due to an increased opioid restraint on the normal progression of pubertal processes. It was also documented that alcohol decrease hypothalamic secretion of LHRH levels ${ }^{53}$. Moreover, these same authors reported that alcohol increased hypothalamic growth hormone releasign hormone (GRH) content which was associated with a decrease in circulating growtth hormone $(\mathrm{GH})^{54}$, suggesting that alcohol decreased $\mathrm{GH}$ secretion as a result of decreased $\mathrm{GRH}$ release from the hypothalamus. This alcohol-induced decrease in GH was also associated with a decrease in circulating IGF-I, which could explain the growth impairments observed in animals administered alcohol ${ }^{55}$. 
In another study on immature female rhesus macaques, it was shown that alcohol consumption $(2 \mathrm{~g} / \mathrm{kg})$ for 12 months resulted in the suppression of the night-related increase in circulating growth hormone $(\mathrm{GH})$ that is expected to occur during late juvenile development. This effect of alcohol was associated with a significant decline in circulating IGF-I, LH and estrogen levels which were most pronounced at 32 months of age. FSH and leptin levels however were not altered by alcohol consumption. The authors also found that alcohol affected the monthly pattern of menstruation which was reflected by lengthening of the intervals between menses ${ }^{56}$. In a more recent study, the same group of researchers suggested that the alcohol damaging action on ovaries is partly mediated through an elevated ovarian nitric oxide synthase and suppressed steroidogenic acute regulatory protein, two important intermediates in steroid hormone production ${ }^{57}$. These studies demonstrate that alcohol abuse induces hormonal alterations of HPG axis and GH/IGF-I axis during puberty. HPG activity and GH/IGFI secretion during this stage of development are closely interconnected. In fact, estrogen can stimulate GH secretion ${ }^{58}$ and IGFI can stimulate LHRH secretion $^{59}$ suggesting that HPG axis activation leads to both sexual maturation and a growth spurt mediated through estrogen-induced stimulation of the GH--IGF axis. Therefore, alcohol-induced disturbances in HPG axis activity, during this critical stage of development, could have far reaching consequences on reproductive function as well as growth which might persist through adult life.

2.3 Alcohol and the female hypothalamic-pituitary-gonadal axis-Alcohol use in premenopausal women, even in moderate amounts, was linked to a multitude of reproductive disorders such as irregular menstrual cycles, anovulation, increased risk of spontaneous abortions and early menopause. Jensen et al. ${ }^{60}$ in a study on 430 healthy women age 20 to 35 years who were trying to conceive for the first time, found that alcohol intake, even as few as five or less drinks per week, was associated with decreased fecundability. In another study on 26 healthy nonalcoholic women that were classified as heavy ( $7.81 \mathrm{drinks} /$ day), social ( $\sim 3.84$ drinks/day) and occasional ( $\sim 1.22 \mathrm{drinks} /$ day $)$ alcohol users, Mendelson and Mello found that $50 \%$ of social drinkers and $60 \%$ of heavy drinkers had significant disturbances of reproductive hormones and of menstrual cycle compared to occasional drinkers and the social drinkers who consumed less than 3 drinks/ day. Social drinkers had anovulatory cycles and heavy drinkers had hyperprolactinemia ${ }^{61,62}$. It was reported that alcohol intake increases estradiol levels in humans ${ }^{63}$ and in rodents ${ }^{64}$. The elevated estradiol level may in part explain the negative effect of alcohol on menstrual cycle and on its irregularity. Long-term moderate alcohol consumption was also shown to decrease ovarian reserve which was associated with increased FSH levels ${ }^{65}$. Faut and colleagues ${ }^{66}$ have suggested that an in-situ metabolism of ethanol to acetaldehyde increases the susceptibility of rat ovarian tissue to oxidative stress and leads to cell damage and ovarian dysfunction.

In postmenopausal women receiving hormone therapy, acute exposure to alcohol induces a temporary increase in estradiol levels which might be due to impaired estradiol metabolism, with decreased conversion of estradiol to estrone. In contrast, alcohol exposure had no effect on estradiol levels in women who were not receiving hormone therapy 67 .

\subsection{Alcohol and the male hypothalamic-pituitary-gonadal axis-There are} numerous studies in animals and humans that amply document the deleterious effects of alcohol on male reproductive function. Associations between both acute and chronic alcohol consumption and lower testosterone levels have been clearly demonstrated. Muthusami and colleagues, in a study on 66 alcoholic and 30 non-alcoholic men, found that chronic alcohol consumption significantly increased FSH, LH, and estrogen levels, whereas testosterone and progesterone were significantly decreased and prolactin (PRL) unchanged. Semen volume, sperm count, motility, and number of morphologically normal sperm were also significantly 
lower in alcoholic group ${ }^{68}$. Alcohol abuse results in hypogonadism even in the absence of liver disease. Alcoholic men with cirrhosis have elevated circulating estradiol and estrone levels ${ }^{69}$. Ethanol increases aromatase activity, an enzyme that converts androgens to estrogens, especially in the liver ${ }^{70}$. A decrease in IGF-I bioavailability as a result of liver disease, contributes at least in part to the development of hypogonadism associated with cirrhosis $^{71}$ since IGF-I is known to stimulate testosterone synthesis and spermatogenesis ${ }^{72}$.

Both acute and chronic exposure of pubertal young male rats to alcohol induced a profound decrease in testosterone concentration that was associated with lower or normal LH and FSH levels, which is abnormal given that low testosterone in normal conditions signals to the hypothalamus to produce LHRH which in turn stimulates LH and FSH secretion and therefore stimulation of testis to produce testosterone ${ }^{73}$. However, in an another study these authors found that chronic ethanol feeding in pubertal male rats significantly decreased testosterone but did not produce any changes in circulating FSH and LH levels ${ }^{74}$. These authors also found that chronic ethanol exposure induced an increase in free radical damage at the pituitary level resulting in inappropriate serum levels of FSH and LH in response to lower testosterone ${ }^{74}$.

Alcohol metabolism, by generating highly toxic reactive oxygen species, such as anion superoxide, hydrogen peroxide, hydroxyl radicals, can induce cell damage in the testes. It was shown that acetaldehyde, a metabolite of alcohol, was more toxic than alcohol alter testosterone production by inhibiting protein kinase $\mathrm{C}$, a key enzyme in testosterone synthesis ${ }^{75,76}$. Nitric oxide (NO), also synthesized in the testes, has been suggested as another player in the alcohol's reduced production of testosterone. Inhibition of the NO synthase (NOS), enzyme responsible for NO synthesis, prevents the decrease in testosterone associated with alcohol drinking 77 .

2.5. Alcohol and Pituitary Prolactin-Prolactin's action on the mammary gland and in the maintenance of lactation has long been known and, indeed, is the source of the name for this hormone. It is one of the most abundant hormones in the pituitary gland and is produced and secreted by lactrope cells. Common manifestations of elevation of plasma PRL (hyperprolactinemia) in women include amenorrhea (lack of menstrural cycles) and galactorrhea (excessive secretion of milk). Men with hyperprolactinemia typically show hypogonadism, with decreased sex drive, low sperm production and impotence. Such men often show breast enlargement (gynecomastia), but very rarely produce milk. A pituitary microadenoma or hyperplasia is the cause of hyperprolactinemia in most patients ${ }^{78}$.

There are several reports showing evidence for the existence of hyperprolactinemia in chronic alcoholic men and women. In a study conducted by European scientists, persistent hyperprolactinemia was observed in 16 alcoholic women during a 6-week treatment trial ${ }^{79}$. These patients reported daily alcohol intake of $170 \mathrm{~g}$ for a 2- to 16-year period but had no clinical evidence of alcoholic liver cirrhosis. In a study reported by Japanese scientists, 22 of 23 women admitted for alcoholism treatment had PRL levels above normal, ranging between 27 and $184 \mathrm{ng} / \mathrm{ml}$. These women reported drinking an average of $84 \mathrm{~g}$ of alcohol each day for at least 7 years. None of these patients showed liver cirrhosis, but 10 had hepatitis and the rest had fatty liver ${ }^{80}$. Studies conducted in a Massachusetts hospital reported hyperprolactinemia (22-87 ng/ml) in 6 of 12 alcohol-dependent women who had a history of drinking $75-247 \mathrm{~g}$ of alcohol per day for a minimum period of 7 years ${ }^{81}$. Alcoholinduced hyperprolactinemia was also reported in healthy, well-nourished women during residence on a clinical research ward for 35 days $^{62}$. Sixty percent of women in the heavy drinker category (blood alcohol level, BAC: $109-199 \mathrm{mg} / \mathrm{dl}$ ) and 50 percent of moderate drinkers (BAC: $48-87 \mathrm{mg} / \mathrm{dl}$ ) showed elevated PRL levels, and many of these drinkers had elevated PRL several days after cessation of drinking. Alcohol-induced hyperprolactinemia 
was also evident in 66 postmenopausal women ${ }^{82}$. Alcoholic men also showed elevated plasma levels of PRL ${ }^{83,84}$. Thus, it appears that chronic alcohol intake in humans promotes hyperprolactinemia.

Alcohol-induced hyperprolactinemia has also been demonstrated in nonhuman primates and laboratory animals. Studies conducted in macaque female monkeys showed that the PRL levels were elevated after chronic self-administration of alcohol $(3.4 \mathrm{~g} / \mathrm{kg} / \mathrm{day})^{85,86}$. Interestingly, histological examination of the pituitary gland of one monkey showed apparent pituitary hyperplasia ${ }^{86}$. Using the laboratory rats, we have shown that ethanol increases plasma PRL levels and pituitary weight in cyclic female rats and ovariectomized rats $^{87}$, and promotes estradiol-induced development of prolactinomas ${ }^{88}$. Therefore, the clinical data as well as animal data suggest that ethanol consumption is a positive risk factor for prolactinomas and hyperprolactinemia.

\section{Alcohol and the hypothalamic-pituitary-thyroid axis}

The hypothalamic-pituitary-thyroid axis is responsible for the regulation of metabolism in every cell in the body. When circulating levels of thyroid hormones, thyroxin (T4) and triiodothyronine (T3) are low, the hypothalamus responds by releasing thyrotropin-releasing hormone (TRH), which then stimulates thyrotrope cells in the anterior pituitary to produce and secrete thyroid-stimulating hormone (TSH). TSH then stimulates the synthesis and secretion of T4 and T3 from the thyroid gland. T3 is the active form of thyroid hormones and although T4 and T3 are both secreted following TSH stimulation, 80\% of circulating T3 comes from liver conversion of T4 by enzymes called deiodinases. T4, but primarily T3 by negative feedback at the hypothalamus and the pituitary, can control their own release by inhibiting TRH and TSH release ${ }^{89}$.

Alcoholic individuals often show dysregulations of the hypothalamic-pituitary-thyroid axis. A significant reduction in $\mathrm{T} 4$ and $\mathrm{T} 3$ concentrations was observed in the alcoholic groups during withdrawal and early abstinence, compared to non-alcoholic healthy groups 90 . In addition a blunted response of TSH to TRH has been consistently reported in alcoholics and during early withdrawal and was positively correlated with severity of withdrawal symptoms $^{91}$. It was also documented that, after longer periods of abstinence, thyroid dysfunction recovers and thyroid hormones and TSH response to TRH return to normal levels ${ }^{91}$. However, in individuals who relapsed and returned to their alcohol drinking behavior, lower T4 and T3 and a blunted TSH response to TRH were again observed ${ }^{92}$.

Similar results were found in studies done on animal models. For example, chronic alcohol administration to adult male rats in a liquid diet containing $10 \%(\mathrm{w} / \mathrm{v})$ ethanol for 40 days induced a significant decrease in total T4 and T3, free T4 and T3 as well as basal TSH when compared to control animals fed an isocaloric diet ${ }^{93}$. In addition, chronic ethanol treatment was shown to induce an increase in TRH mRNA content in neurons of the PVN, however the peripheral stimulation of thyroid hormones by cold exposure was absent in rats ${ }^{94}$, suggesting that chronic exposure to ethanol induces thyroid gland dysfunction, which no longer is able to properly respond to TRH stimulation. Furthermore, down-regulation of TRH receptors in the pituitary has been proposed as a mechanism by which chronic alcohol induces the blunted TSH response to TRH.

Other mechanisms for ethanol action on HPT axis have been proposed, which focused on thyroid hormone metabolism and on the activity of enzymes that catalyze the conversion of T4 to T3 (5'II deiodinase) and inactivate T3 to 3,3"-T2 (5-II deiodinase). Baumgartner et al. 95 in a study in "behaviorally dependent" and ethanol-exposed but "not dependent" rats, found that the activity of the 5'II deiodinase isoenzyme was elevated in the frontal cortex in both groups of' rats. The activity of the 5-II deiodinase isoenzyme, however, was selectively 
inhibited in the amygdala of the rats who were "behaviorally dependent" on ethanol, but was normal in the "non-dependent" rats. These authors suggested that increases in intracellular concentrations of T3 in the amygdala may be involved in the development of dependence behaviors to alcohol.

\section{Alcohol and growth hormone insulin-like growth factor-1 axis}

In the hypothalamic-pituitary-growth hormone-IGF-1 axis, growth hormone releasing hormone (GHRH) is secreted from cells in the arcuate and ventromedial nuclei of the hypothalamus into the hypophyseal portal system. GHRH then acts on somatotropic cells in the anterior pituitary where it stimulates the production and release of $\mathrm{GH}$, which is then released in the general circulation and stimulates IGF-1 mainly in the liver. IGF-I through negative feedback at the hypothalamus and pituitary reduces GH synthesis and release. Another hormone called somatostatin, which is secreted in the PVN of the hypothalamus also acts on the pituitary and inhibits GH secretion. Between GHRH, somatostatin and IGFI, the amount of GH secreted by the anterior pituitary is tightly regulated. Together GH and IGF-I regulate important physiological processes in the body such as, postnatal growth and development, carbohydrate and lipid metabolism ${ }^{96}$. Numerous studies in both humans and experimental animals have shown that acute and chronic alcohol exposure reduces circulating GH and IGF-I levels. Acute exposure of healthy men to ethanol $(1.5 \mathrm{~g} / \mathrm{kg})$ was shown to reduce the nightly peak of GH secretion ${ }^{97}$. This effect did not seem to be mediated through a direct action of ethanol on the pituitary rendering it less sensitive to GHRH since intravenous injection of exogenous GHRH induced an increase in GH secretion in both groups ethanol-treated $(1 \mathrm{~g} / \mathrm{kg})$ and control $\mathrm{men}^{98}$. However, an acute exposure of healthy women to ethanol had no significant effects on $\mathrm{GH}$ secretion ${ }^{99}$. Sonntag and Boyd ${ }^{100}$ found that, in rats exposed to $5 \%$ ethanol in a liquid diet for 4.5 months ethanol induced a significant decrease in circulating IGF-1 levels. Soszynski and colleagues reported, that a 6 day administration of 5\% ethanol to chronically cannulated unanesthetized rats resulted in 75 to $90 \%$ decrease in spontaneous GH secretion in rats ${ }^{101}$. In addition, IGF-I serum levels and GHRH mRNA levels were significantly decreased with no change in somatostatin or GH mRNA levels following ethanol treatments ${ }^{102}$. These results suggest that chronic ethanol affects GH secretion primarily at the hypothalamic level where it induces impairments in GHRH gene expression.

Chronic alcohol consumption was shown to induce muscle wasting ${ }^{103}$ and since IGF-I is a potent anabolic agent that regulates muscle protein balance, this next study showed that rats fed ethanol for 8 weeks had significantly lower IGF-I in plasma, liver and skeletal muscle compared to pair-fed control ${ }^{104}$. The IGF-I mRNA level was also lower in liver and skeletal muscle. However, the concentration of IGF binding protein (IGFBP)-1 was increased in plasma, liver and muscle; and no changes in glucocorticoids or insulin or GH were reported in these ethanol-fed rats compared with controls ${ }^{104}$. These results suggest that the ethanol mediated-changes in IGF-I and IGFBP-I concentrations are mediated through mechanisms that are independent of classical hormonal regulators of the IGF system (i.e. GH, high glucocorticoids and low insulin-induced hypoglycemia).

\section{Alcohol and circadian rhythm}

In all organisms, especially in mammals, a time-keeping system called the master circadian pacemaker located in the suprachiasmatic nucleus $(\mathrm{SCN})$ of the anterior hypothalamus synchronizes biological rhythms in response to external cues. The circadian rhythm generated in the SCN, in response to external cues such as day light, is converted into neuronal or hormonal signals that affect the entire body's physiological and metabolic processes, thereby optimizing the organism's interaction with changing environmental conditions. The circadian clockwork involves the interaction of specific clock genes, 
including Period (Per1, Per2, Per3), Clock, Bmal1, and Cryptochrome (Cry1, Cry2) genes within two tightly interlocked transcriptional and translational feedback loops that sustain a near $24 \mathrm{~h}$ period of cellular activity and regulates the expression of downstream clockcontrolled genes. These processes occur not only in the master pacemaker, the suprachiasmatic nucleus, but also in other regions of the brain as well as in the peripheral cells in the entire body ${ }^{105,106 .}$

Numerous studies in both, humans and animal models, showed that chronic exposure to alcohol induces alterations in the activity of clock genes resulting in severe desynchronizations of physiological clock systems such as sleep, body temperature, blood pressure and hormonal secretions; and vice versa clock genes influence alcohol use and abuse behavior ${ }^{107}$. Our own work have shown that chronic exposure of prenatal or postnatal rats to ethanol induces alterations in the circadian expression of POMC and the clock genes $\mathrm{r} P e r 1, \mathrm{r} P e r 2$ and $\mathrm{r} P e r 3$ in the arcuate nucleus and $\mathrm{r} P$ er 1 and $\mathrm{r} P e r 2$ levels in SCN during the adult period ${ }^{108}$.

The circadian clock and clock gene activity not only controls the sleep/wake and feeding/ fasting behavior, but it also influences hormone release. The different endocrine axes function is under tight circadian control and dysregulations in the activity of clock genes might therefore affect the oscillatory characteristic of hormone secretion. Jimenez and colleagues ${ }^{109}$, in a study on peripubertal male rats, showed that chronic alcohol exposure for 4 weeks not only induced significant changes in hypothalamic-pituitary hormone levels but also affected their 24 hour secretory pattern. Two peaks of FSH during the inactive phase of the daily cycle appeared instead of one, no LH plasma surge during the first part of the inactive phase, a second peak of testosterone and prolactin during the second part of the inactive phase and a second peak of plasma TSH during the first part of the active phase were observed. In addition, an interaction between circadian clock and HPA axis responsiveness to stress has been consistently linked to alcohol abuse and dependence. Stress is regarded as a major environmental risk factor for both, heavy drinking ${ }^{110}$ and disturbed circadian rhythmicity ${ }^{110,111}$. In a study on 268 young adults (126 males, 142 females) 19 years of age, a positive association between the major A allele of PER2 rs56013859 and alcohol consumption was found in homozygote individuals ${ }^{112}$. Moreover, under conditions of stress carriers of the $\mathrm{G}$ allele drunk less than those homozygous for the A allele. These findings suggest a role of a PER 2 gene variant in both the drinking patterns as well as the stress responsiveness. In another study, Per3 gene was also linked to stress/ anxiety traits and its basal expression correlated with addiction-related phenotypes. Exposure to alcohol increased Per 3 expression in the hippocampus, and this was shown to affect stress response ${ }^{113}$. In animal studies, it was shown that Per2 mutant mice had impairments in the glutamate transporter Eaat 1 resulting in decreased glutamate uptake by astrocytes and its accumulation in the extracellular milieu; this was associated with increased alcohol intake in these Per2 mutant mice ${ }^{114}$. These researchers found that treating these Per 2 mutant mice with acamprosate, a drug used in relapse prevention of alcoholism which is thought to attenuate the hyper-glutamatergic state, reduced the increased glutamate levels and normalized alcohol intake in these mice. A significant association between a single nucleotide polymorphism variation in the human Per2 gene, PER2 SNP 10870, (A/G substitution) and regulation of alcohol consumption was shown in a clinical sample of severe alcoholics ${ }^{114}$. In addition to this interaction between the stress and circadian rhythm, a large number of data suggest that the disruption in circadian clocks mechanism negatively impact immune system functions and promotes cancer susceptibility ${ }^{115}, 116$. Taken together, these studies suggest the important role that clock genes play in the alcohol-mediated dysregulation of the circadian nature of endocrine function as well as in the alcohol preference and abuse behaviors. 


\section{Alcohol and pancreatic function}

The pancreas is one of the most important organs of the endocrine system that is involved in the tight control of blood glucose concentration through synthesis and secretion of a peptide hormone called insulin from B-cells. Diabetes mellitus (DM) is a syndrome of dysregulated metabolism with high blood glucose levels (hyperglycemia) due either to an abnormal insulin secretion and/or signaling in peripheral tissues. DM is characterized by either a ß-cell deficit such as in insulin-dependent type 1 diabetes or reduced peripheral insulin sensitivity as in type 2 diabetes. Type 2 diabetes is recognized clinically as a complication which often occurred in alcoholics 117,118 . However, it was shown that the relationship between alcohol consumption and the risk of type 2 diabetes is a "U" shaped.

Low or moderate alcohol consumption shows protective effects against type 2 diabetes in some patients through enhanced peripheral insulin sensitivity ${ }^{119}$. A $30 \%$ reduced risk of type 2 diabetes was observed in patients with moderate alcohol consumption, whereas no risk reduction was observed in consumers of amounts of alcohol equal to or over $48 \mathrm{~g} / \mathrm{day}$. Whether moderate alcohol consumption affects insulin secretion is still very controversial. Some studies show that moderate alcohol consumption improves insulin action without affecting its secretion ${ }^{120}$, whereas others show a reduced basal insulin secretion rate associated with a lower fasting plasma glucagon concentration ${ }^{121}$. Avogaro et al. ${ }^{120}$ have also shown, in the same study, that the enhanced insulin sensitivity observed may be in part due to the inhibitory effect of alcohol on lipolysis. The beneficial metabolic effects of moderate alcohol consumption on insulin sensitivity and glucose tolerance may explain the significant reduction in the development of type 2 diabetes and the risk of cardiovascular disorders reported in several epidemiological studies 120,122 .

Heavy alcohol consumption, on the other hand, is an independent risk factor for the development of Type 2 diabetes mellitus ${ }^{123}$. In addition to its effects on peripheral tissues, such as adipose tissue and liver, where it induces insulin resistance, heavy alcohol consumption was also proposed to negatively impact pancreatic $\beta$-cell function. Patto and colleagues $^{124}$, in a study on 16 healthy volunteer non-alcohol consumers and 10 chronic alcohol consumers, found that there was a decrease in insulin response in the chronic alcohol consumers compared to the control group. They measured total integrated response (TIR) values for Insulin and c-peptide following oral or intravenous glucose loads in these two groups. They found that the insulin and c-peptide TIR values were both significantly lower in the alcoholic group compared to the control group. In addition, in both groups the insulin TIR values following the oral glucose load were significantly higher than those following the intravenous glucose load, suggesting an enhancing incretin effect on insulin secretion. These authors concluded that the decreased insulin response observed in alcoholics was due to a ß-cell dysfunction, not to an enteroinsular axis dysfunction because the decrease was also observed when a glucose load was given intravenously. In another study by Kim and colleagues $^{125}$ it was shown that in mice exposed for 8 to 10 weeks to chronic alcohol, there was a significant increase in the impairment of fasting glucose and an increase in $\beta$-cell apoptosis, which were associated with a reduction in insulin secretion. These effects of chronic ethanol seemed to be mediated through a down-regulation and inactivation by tyrosine nitration of the enzyme glucokinase, a critical player in glucose metabolism that leads to an increased ATP production and therefore to insulin secretion by beta-cells. These effects were also associated with a decrease in Glut2 and insulin expression, which exacerbates alcohol action. In an in-vitro study on RINm5F $\beta$-cell line, it was suggested that ethanol generates reactive oxygen species (ROS) and induces $\beta$-cell apoptosis ${ }^{126}$. All of these studies suggest that heavy alcohol consumption has deleterious effects on pancreatic $\beta$ cell function and on glucose homeostasis. 


\section{Alcohol and immune system}

The neuroendocrine and immune systems are highly interrelated. A bidirectional interaction between both systems has long been recognized; especially the sensitivity of the immune system to stress and its interaction with the HPA axis which was primarily evidenced by the immunosuppressive actions of glucocorticoids especially cortisol which upon binding to its specific receptor (GR) can interfere with signaling pathways of other transcription factors such as NFkB and AP-1 to repress transcription of many inflammatory molecules. In addition, CRH and ACTH were also shown to have immuno-potentiating and proinflammatory properties whereas for example interleukins and cytokines produced by activated macrophages, in an adaptive feedback mechanism, can act on the HPA axis and induce CRH and ACTH secretion. For example, IL-2 was shown to stimulate cholinergic neurons and activate neural nitric oxide synthase (nNOS) which releases nitric oxide (NO). After release, NO diffuses into CRH producing neurons and induces CRH secretion which ultimately leads to ACTH release from anterior pituitary and cortisol from adrenal glands. This bidirectional interaction between HPA axis and immune system is essential for survival and for maintenance of the body's homeostasis. However, in alcohol abuse conditions HPA axis and immune system function is compromised and contributes to a worsened state. Glucocorticoids, at excessive amounts have serious negative effects; first through their immunosuppressive action and second through induced acute and chronic metabolic abnormalities ${ }^{127,128}$.

In recent years, a body of evidence from human as well as animal studies established a link between long-term alcohol use and alterations of both HPA axis and immune system functions. Alcohol abuse disorders are often associated with chronic systemic inflammation and high circulating proinflammatory cytokine levels as well as high circulating cortisol levels. Two mechanisms through which alcohol induces inflammation have been proposed; first, the gut microflora-derived lipopolisacharides (LPS) were suggested as key players in alcohol-mediated inflammation ${ }^{129}$ and second, alcohol metabolism through production of reactive-oxygen species (ROS) and cell damage triggers the production of pro-inflammatory cytokines such as TNF- $a$ and IL- $6{ }^{130}$. An alcohol-induced systemic inflammation that persists, in the case of alcohol abuse, has far reaching damaging actions on every organ of the body. In the brain, alcohol has neurotoxic effects that result in neuronal death and neurodegeneration ${ }^{131,132}$. Alcoholics have been shown to have reduced brain mass, cortical neuronal loss and impaired cognitive functions ${ }^{133,134}$. Studies from our laboratory as well as from others have clearly shown that ethanol exposure during the developmental period induces neurotoxicity and permanent impairments in the stress axis as well as the immune function $131,135,136$. Microglial cells, the macrophage cells in the brain, were shown to play an important role in these neurotoxic effects of alcohol on neuronal cells ${ }^{137-139}$.

Acute or chronic alcohol exposures have both been shown to induce immunosuppression through dysregulation in all branches of the immune system. Alcohol exposure reduces neutrophil (macrophage) infiltration and migration to sites of infection as well as production of new neutrophils in response to infection and their phagocitic activity ${ }^{140,141}$. Chronic alcohol exposure also decreases monocyte phagocytic activity even though the number of these cells is increased ${ }^{142}$. Furthermore, chronic alcohol exposure decreases the number and activity of dendritic and natural-killer cell (NK-cells) ${ }^{143-145}$. Alcohol's effect on cytokine production depends on the length of exposure. For example, acute exposure to ethanol is associated with suppression of cytokine production (i.e. TNFa and IL1ß ${ }^{146}$. However, chronic exposure to alcohol induces an increase in pro-inflammatory cytokine production such as that of $\mathrm{TNFa}^{147,148}$. In addition, alcohol exposure suppresses chemokine production, such as that of MIP2 (macrophage inflammatory protein 2) and IFNY (interferon gamma) which were shown to be suppressed following acute exposure to ethanol ${ }^{149,150}$. All these studies clearly suggest that ethanol disruption of cytokines and inflammation 
contributes in a multitude of ways to a diversity of alcoholic disorders. These alcoholinduced suppressive effects on the immune function were shown to be primarily due to a blunted response of the HPA axis to external stressors such as infections. In this context it is notable that stress axis dysfunction is positively connected with not only immune incompetence but also promotion of various cancers ${ }^{11,151}$. More studies are needed to further understand and identify the mechanisms that underlie the bidirectional interactions between immune and endocrine system in the case of alcohol-related disorders which will help in the management and treatment of these disorders.

\section{Acknowledgments}

Funding: Supported by NIAAA grants 5R37 AA08757, AA11591, U24 AA014811

\section{Abbreviation used}

$\mathbf{A A}$

АCTH

ANA

ANS

AP-1

BAC

BEP

CRH

DA

DM

FSH

GH

GnRH

GR

GRH

HPA

HPG

HPT

IFNY

IGF-1

IGFBP-1

IL-13

IL-6

LDL

LH

LHRL alcohol preferring

adrenocorticotropic hormone

alcohol non-preferring

autonomic nervous system

activator protein 1

blood alcohol concentration

ß-endorphin

corticotropin-releasing hormone

dopamine

diabetes mellitus

follicle-stimulating hormone

growth hormone

gonadotropin-releasing hormone

glucocorticoid receptor

growth hormone-releasing hormone

hypothalamic pituitary adrenal

hypothalamic pituitary gonadal

hypothalamic pituitary thyroid

interferon gamma

Insulin-like growth factor-1

IGF binding protein 1

interleukin-1ß

interleukin-6

low density lipoproteins

luteinizing hormone

Luteinizing hormone-releasing hormone 


\begin{tabular}{ll} 
LPS & lipopolisaccharides \\
MIP2 & macrophage inflammatory protein 2 \\
MR & mineralocorticoid receptors \\
NFkB & nuclear factor kB \\
NK cells & natural killer cells \\
NMDA & N-methyl-D-aspartate \\
NO & nitric oxide \\
NOS & nitric oxide synthase \\
NOS & nitric oxide synthase \\
NR2B & NMDA receptor 2B \\
Per & period \\
POMC & proopiomelanocortin \\
PRL & prolactin \\
PVN & praventricular nucleus \\
ROS & reactive oxygen species \\
SCN & suprachiasmatic nucleus \\
SNS & sympathetic nervous system \\
T3 & triiodothyronine \\
T4 & thyroxin \\
TGF-a & transforming growth factor alpha \\
TIR & total integrated response \\
TNF-a & tumor necrosis factor-alpha \\
TSH & thyroid-stimulating hormone \\
\hline
\end{tabular}

\section{Reference List}

1. Grant BF, Dawson DA, Stinson FS, et al. The 12-month prevalence and trends in DSM-IV alcohol abuse and dependence: United States, 1991-1992 and 2001-2002. Drug Alcohol Depend. 2004; 74:223-234. [PubMed: 15194200]

2. Dick DM, Bierut LJ. The genetics of alcohol dependence. Curr.Psychiatry Rep. 2006; 8:151-157. [PubMed: 16539893]

3. Ducci F, Goldman D. Genetic approaches to addiction: genes and alcohol. Addiction. 2008; 103:1414-1428. [PubMed: 18422824]

4. Corbin WR, Farmer NM, Nolen-Hoekesma S. Relations among stress, coping strategies, coping motives, alcohol consumption and related problems: a mediated moderation model. Addict. Behav. 2013; 38:1912-1919. [PubMed: 23380486]

5. Edwards G, Anderson P, Babor TF, et al. Alcohol policy and the public good: a good public debate. Addiction. 1996; 91:477-481. [PubMed: 8857369]

6. Rehm JT, Bondy SJ, Sempos CT, et al. Alcohol consumption and coronary heart disease morbidity and mortality. Am.J Epidemiol. 1997; 146:495-501. [PubMed: 9290510]

7. Berger K, Ajani UA, Kase CS, et al. Light-to-moderate alcohol consumption and risk of stroke among U.S. male physicians. N.Engl.J Med. 1999; 341:1557-1564. [PubMed: 10564684] 
8. Calabrese G. Nonalcoholic compounds of wine: the phytoestrogen resveratrol and moderate red wine consumption during menopause. Drugs Exp.Clin.Res. 1999; 25:111-114. [PubMed: 10370872]

9. Emanuele N, Emanuele MA. The endocrine system: alcohol alters critical hormonal balance. Alcohol Health Res.World. 1997; 21:53-64. [PubMed: 15706763]

10. Kusnecov, A.; Anisman, H., editors. The Wiley-Blackwell Handbook of Psychoneuroimmunlogy. Wiley-Blackwell; Oxford: 2013.

11. Wynne, O.; Sarker, DK. Stress and neuroendocrine-immune interaction: a therapeutic role for âendorphin. In: Kusnecov, A.; Anisman, H., editors. The Wiley-Blackwell Handbook of Psychoneuroimmunlogy. Wiley-Blackwell; Oxford: 2013.

12. Rivier C, Lee $\mathrm{S}$. Acute alcohol administration stimulates the activity of hypothalamic neurons that express corticotropin-releasing factor and vasopressin. Brain Res. 1996; 726:1-10. [PubMed: 8836539]

13. Rivier C, Bruhn T, Vale W. Effect of ethanol on the hypothalamic-pituitary-adrenal axis in the rat: role of corticotropin-releasing factor (CRF). J Pharmacol.Exp.Ther. 1984; 229:127-131. [PubMed: 6323684]

14. Ogilvie KM, Lee S, Rivier C. Role of arginine vasopressin and corticotropin-releasing factor in mediating alcohol-induced adrenocorticotropin and vasopressin secretion in male rats bearing lesions of the paraventricular nuclei. Brain Res. 1997; 744:83-95. [PubMed: 9030416]

15. Jenkins JS, Connolly J. Adrenocortical response to ethanol in man. Br.Med.J. 1968; 2:804-805. [PubMed: 5656299]

16. Thayer JF, Hall M, Sollers JJ III, et al. Alcohol use, urinary cortisol, and heart rate variability in apparently healthy men: Evidence for impaired inhibitory control of the HPA axis in heavy drinkers. Int.J Psychophysiol. 2006; 59:244-250. [PubMed: 16325293]

17. Richardson HN, Lee SY, O’Dell LE, et al. Alcohol self-administration acutely stimulates the hypothalamic-pituitary-adrenal axis, but alcohol dependence leads to a dampened neuroendocrine state. Eur.J Neurosci. 2008; 28:1641-1653. [PubMed: 18979677]

18. Rasmussen DD, Boldt BM, Bryant CA, et al. Chronic daily ethanol and withdrawal: 1. Long-term changes in the hypothalamo-pituitary-adrenal axis. Alcohol Clin.Exp Res. 2000; 24:1836-1849. [PubMed: 11141043]

19. Sarnyai Z, Shaham Y, Heinrichs SC. The role of corticotropin-releasing factor in drug addiction. Pharmacol.Rev. 2001; 53:209-243. [PubMed: 11356984]

20. Olive MF, Mehmert KK, Koenig HN, et al. A role for corticotropin releasing factor (CRF) in ethanol consumption, sensitivity, and reward as revealed by CRF-deficient mice. Psychopharmacology (Berl). 2003; 165:181-187. [PubMed: 12397512]

21. Barr CS, Dvoskin RL, Gupte M, et al. Functional CRH variation increases stress-induced alcohol consumption in primates. Proc.Natl.Acad.Sci.U.S.A. 2009; 106:14593-14598. [PubMed: 19706546]

22. Sillaber I, Rammes G, Zimmermann S, et al. Enhanced and delayed stress-induced alcohol drinking in mice lacking functional CRH1 receptors. Science. 2002; 296:931-933. [PubMed: 11988580]

23. Holter SM, Danysz W, Spanagel R. Novel uncompetitive N-methyl-D-aspartate (NMDA)-receptor antagonist MRZ 2/579 suppresses ethanol intake in long-term ethanol-experienced rats and generalizes to ethanol cue in drug discrimination procedure. J Pharmacol.Exp.Ther. 2000; 292:545-552. [PubMed: 10640291]

24. Koob GF. Brain stress systems in the amygdala and addiction. Brain Res. 2009; 1293:61-75. [PubMed: 19332030]

25. Koob GF, Le Moal M. Drug abuse: hedonic homeostatic dysregulation. Science. 1997; 278:52-58. [PubMed: 9311926]

26. Roberts AJ, Heyser CJ, Cole M, et al. Excessive ethanol drinking following a history of dependence: animal model of allostasis. Neuropsychopharmacology. 2000; 22:581-594. [PubMed: 10788758]

27. Krishnan S, Maickel RP. The effect of Hoe-427 (an ACTH4-9 analog) on free-choice ethanol consumption in male and female rats. Life Sci. 1991; 49:2005-2011. [PubMed: 1660954] 
28. Fahlke C, Eriksson CJ. Effect of adrenalectomy and exposure to corticosterone on alcohol intake in alcohol-preferring and alcohol-avoiding rat lines. Alcohol Alcohol. 2000; 35:139-144. [PubMed: 10787388]

29. Fahlke C, Hansen S. Effect of local intracerebral corticosterone implants on alcohol intake in the rat. Alcohol Alcohol. 1999; 34:851-861. [PubMed: 10659720]

30. Oswald LM, Wand GS. Opioids and alcoholism. Physiol Behav. 2004; 81:339-358. [PubMed: 15159175]

31. Calogero AE. Neurotransmitter regulation of the hypothalamic corticotropin-releasing hormone neuron. Ann.N.Y.Acad.Sci. 1995; 771:31-40. [PubMed: 8597409]

32. Gianoulakis C. Influence of the endogenous opioid system on high alcohol consumption and genetic predisposition to alcoholism. J Psychiatry Neurosci. 2001; 26:304-318. [PubMed: 11590970]

33. Wand GS, Mangold D, Ali M, et al. Adrenocortical responses and family history of alcoholism. Alcohol Clin.Exp.Res. 1999; 23:1185-1190. [PubMed: 10443984]

34. Schuckit MA. Subjective responses to alcohol in sons of alcoholics and control subjects. Arch.Gen.Psychiatry. 1984; 41:879-884. [PubMed: 6466047]

35. Cintra A, Zoli M, Rosen L, et al. Mapping and computer assisted morphometry and microdensitometry of glucocorticoid receptor immunoreactive neurons and glial cells in the rat central nervous system. Neuroscience. 1994; 62:843-897. [PubMed: 7870311]

36. Fahlke C, Hard E, Thomasson R, et al. Metyrapone-induced suppression of corticosterone synthesis reduces ethanol consumption in high-preferring rats. Pharmacol.Biochem.Behav. 1994; 48:977-981. [PubMed: 7972304]

37. Sarkar DK, Chiappa SA, Fink G, Sherwood NM. Gonadotropin-releasing hormone surge in prooestrous rats. Nature. 1976; 264:461-463. [PubMed: 794737]

38. Prendergast, K.; Heras-Herzig, A.; Dalkin, A. GNRH-Gonadotrophins Physiology and Pathology. 2008. Endotext.com

39. Imai Y, Youn MY, Kondoh S, et al. Estrogens maintain bone mass by regulating expression of genes controlling function and life span in mature osteoclasts. Ann.N.Y.Acad.Sci. 2009; 1173(Suppl 1):E31-E39. [PubMed: 19751412]

40. Seifert-Klauss V, Schmidmayr M, Hobmaier E, et al. Progesterone and bone: a closer link than previously realized. Climacteric. 2012; 15(Suppl 1):26-31. [PubMed: 22432813]

41. Oury F. A crosstalk between bone and gonads. Ann.N.Y.Acad.Sci. 2012; 1260:1-7. [PubMed: 22239174]

42. Patrelli TS, Gizzo S, Franchi L, et al. A prospective, case-control study on the lipid profile and the cardiovascular risk of menopausal women on oestrogen plus progestogen therapy in a northern Italy province. Arch.Gynecol.Obstet. 2013

43. Seftel A. Male hypogonadism. Part II: etiology, pathophysiology, and diagnosis. Int.J Impot.Res. 2006; 18:223-228. [PubMed: 16094414]

44. Ackermann S, Spalek K, Rasch B, et al. Testosterone levels in healthy men are related to amygdala reactivity and memory performance. Psychoneuroendocrinology. 2012; 37:1417-1424. [PubMed: 22341731]

45. Sarkar DK, Fink G. Mechanism of the first spontaneous gonadotrophin surge and that induced by pregnant mare serum and effects of neonatal androgen in rats. J Endocrinol. 1979; 83:339-354. [PubMed: 395267]

46. Ojeda SR, Prevot V, Heger S, Lomniczi A, Dziedzic B, Mungenast A. The neurobiology of female puberty. Horm Res. 2003; 60(Suppl 3):15-20. [PubMed: 14671391]

47. Ojeda SR, Lomniczi A, Sandau U, Matagne V. New concepts on the control of the onset of puberty. Endocr Dev. 2010; 17:44-51. [PubMed: 19955755]

48. Terasawa E, Fernandez DL. Neurobiological mechanisms of the onset of puberty in primates. Endocr.Rev. 2001; 22:111-151. [PubMed: 11159818]

49. Block GD, Yamamoto ME, Mallick A, et al. Effects on pubertal hormones by ethanol abuse in adolescents. Alcohol: Clin Exp Res. 1993; 17:505. 
50. Diamond F Jr. Ringenberg L, MacDonald D, et al. Effects of drug and alcohol abuse upon pituitary-testicular function in adolescent males. J Adolesc.Health Care. 1986; 7:28-33. [PubMed: 2935515]

51. Bo WJ, Krueger WA, Rudeen PK, et al. Ethanol-induced alterations in the morphology and function of the rat ovary. Anat.Rec. 1982; 202:255-260. [PubMed: 7199834]

52. Emanuele N, Ren J, Lapaglia N, et al. EtOH disrupts female mammalian puberty: age and opiate dependence. Endocrine. 2002; 18:247-254. [PubMed: 12450316]

53. Hiney JK, Dees WL. Ethanol inhibits luteinizing hormone-releasing hormone release from the median eminence of prepubertal female rats in vitro: investigation of its actions on norepinephrine and prostaglandin-E2. Endocrinology. 1991; 128:1404-1408. [PubMed: 1999162]

54. Dees WL, Skelley CW. Effects of ethanol during the onset of female puberty. Neuroendocrinology. 1990; 51:64-69. [PubMed: 2106089]

55. Dees WL, Srivastava V, Hiney JK. Actions and interactions of alcohol and insulin-like growth factor-1 on female pubertal development. Alcohol Clin.Exp.Res. 2009; 33:1847-1856. [PubMed: 19719789]

56. Dees WL, Dissen GA, Hiney JK, et al. Alcohol ingestion inhibits the increased secretion of puberty-related hormones in the developing female rhesus monkey. Endocrinology. 2000; 141:1325-1331. [PubMed: 10746635]

57. Srivastava VK, Dissen GA, Ojeda SR, et al. Effects of alcohol on intraovarian nitric oxide synthase and steroidogenic acute regulatory protein in the prepubertal female rhesus monkey. $\mathrm{J}$ Stud.Alcohol Drugs. 2007; 68:182-191. [PubMed: 17286336]

58. Mauras N, Rogol AD, Haymond MW, et al. Sex steroids, growth hormone, insulin-like growth factor-1: neuroendocrine and metabolic regulation in puberty. Horm.Res. 1996; 45:74-80. [PubMed: 8742123]

59. Hiney JK, Srivastava V, Lara T, et al. Ethanol blocks the central action of IGF-1 to induce luteinizing hormone secretion in the prepubertal female rat. Life Sci. 1998; 62:301-308. [PubMed: 9450501]

60. Jensen TK, Hjollund NH, Henriksen TB, et al. Does moderate alcohol consumption affect fertility? Follow up study among couples planning first pregnancy. BMJ. 1998; 317:505-510. [PubMed: 9712595]

61. Mendelson JH, Lukas SE, Mello NK, et al. Acute alcohol effects on plasma estradiol levels in women. Psychopharmacology (Berl). 1988; 94:464-467. [PubMed: 3131791]

62. Mendelson JH, Mello NK. Chronic alcohol effects on anterior pituitary and ovarian hormones in healthy women. J Pharmacol.Exp.Ther. 1988; 245:407-412. [PubMed: 3367299]

63. Muti P, Trevisan M, Micheli A, et al. Alcohol consumption and total estradiol in premenopausal women. Cancer Epidemiol.Biomarkers Prev. 1998; 7:189-193. [PubMed: 9521430]

64. Emanuele NV, Lapaglia N, Steiner J, et al. Effect of chronic ethanol exposure on female rat reproductive cyclicity and hormone secretion. Alcohol Clin.Exp.Res. 2001; 25:1025-1029. [PubMed: 11505028]

65. Li N, Fu S, Zhu F, et al. Alcohol intake induces diminished ovarian reserve in childbearing age women. J Obstet.Gynaecol.Res. 2013; 39:516-521. [PubMed: 23002912]

66. Faut M, Rodriguez dC, Bietto FM, et al. Metabolism of ethanol to acetaldehyde and increased susceptibility to oxidative stress could play a role in the ovarian tissue cell injury promoted by alcohol drinking. Toxicol.Ind.Health. 2009; 25:525-538. [PubMed: 19825859]

67. Longnecker MP, Tseng M. Alcohol, hormones, and postmenopausal women. Alcohol Health Res.World. 1998; 22:185-189. [PubMed: 15706794]

68. Muthusami KR, Chinnaswamy P. Effect of chronic alcoholism on male fertility hormones and semen quality. Fertil.Steril. 2005; 84:919-924. [PubMed: 16213844]

69. Martinez-Riera A, Santolaria-Fernandez F, Gonzalez RE, et al. Alcoholic hypogonadism: hormonal response to clomiphene. Alcohol. 1995; 12:581-587. [PubMed: 8590623]

70. Purohit V. Can alcohol promote aromatization of androgens to estrogens? A review. Alcohol. 2000; 22:123-127. [PubMed: 11163119] 
71. Castilla-Cortazar I, Quiroga J, Prieto J. Insulin-like growth factor-I, liver function, and hypogonadism in rats with experimentally induced cirrhosis. Hepatology. 2000; 31:1379. [PubMed: 10866524]

72. Roser JF. Regulation of testicular function in the stallion: an intricate network of endocrine, paracrine and autocrine systems. Anim Reprod.Sci. 2008; 107:179-196. [PubMed: 18571346]

73. Ren JC, Zhu Q, Lapaglia N, et al. Ethanol-induced alterations in Rab proteins: possible implications for pituitary dysfunction. Alcohol. 2005; 35:103-112. [PubMed: 15963423]

74. Ren JC, Banan A, Keshavarzian A, et al. Exposure to ethanol induces oxidative damage in the pituitary gland. Alcohol. 2005; 35:91-101. [PubMed: 15963422]

75. Chiao YB, Van Thiel DH. Biochemical mechanisms that contribute to alcohol-induced hypogonadism in the male. Alcohol Clin.Exp.Res. 1983; 7:131-134. [PubMed: 6307074]

76. Anderson RA Jr. Quigg JM, Oswald C, et al. Demonstration of a functional blood-testis barrier to acetaldehyde. Evidence for lack of acetaldehyde effect on ethanol-induced depression of testosterone in vivo. Biochem.Pharmacol. 1985; 34:685-695. [PubMed: 3977944]

77. Adams ML, Nock B, Truong R, et al. Nitric oxide control of steroidogenesis: endocrine effects of NG-nitro-L-arginine and comparisons to alcohol. Life Sci. 1992; 50:L35-L40.

78. Sarkar DK. Hyperprolactinemia following chronic alcohol administration. Front Horm Res. 2010; 38:32-41. [PubMed: 20616493]

79. Valimaki M, Pelkonen R, Harkonen M, et al. Pituitary-gonadal hormones and adrenal androgens in non-cirrhotic female alcoholics after cessation of alcohol intake. Eur.J Clin.Invest. 1990; 20:177181. [PubMed: 2112483]

80. Seki M, Yoshida K, Okamura Y. A study on hyperprolactinemia in female patients with alcoholics. Arukoru Kenkyuto Yakubutsu Ison. 1991; 26:49-59. [PubMed: 2069537]

81. Teoh SK, Lex BW, Mendelson JH, et al. Hyperprolactinemia and macrocytosis in women with alcohol and polysubstance dependence. J Stud.Alcohol. 1992; 53:176-182. [PubMed: 1560669]

82. Gavaler, JS. Aging and alcohol: the hormonal status of postmenopausal women. In: Sarkar, DK.; Barnes, C., editors. Reproductive Neuroendocrinology of aging and drug abuse. CRC Press; Boca Raton: 1994. p. 365-378.

83. Ida Y, Tsujimaru S, Nakamaura K, et al. Effects of acute and repeated alcohol ingestion on hypothalamic-pituitary-gonadal and hypothalamic-pituitary-adrenal functioning in normal males. Drug Alcohol Depend. 1992; 31:57-64. [PubMed: 1330472]

84. Soyka M, Gorig E, Naber D. Serum prolactin increase induced by ethanol--a dose-dependent effect not related to stress. Psychoneuroendocrinology. 1991; 16:441-446. [PubMed: 1805295]

85. Mello NK, Mendelson JH, Bree MP, et al. Alcohol effects on naloxone-stimulated luteinizing hormone, follicle-stimulating hormone and prolactin plasma levels in female rhesus monkeys. $\mathrm{J}$ Pharmacol.Exp.Ther. 1988; 245:895-904. [PubMed: 3133465]

86. Mello NK, Bree MP, Mendelson JH, et al. Alcohol self-administration disrupts reproductive function in female macaque monkeys. Science. 1983; 221:677-679. [PubMed: 6867739]

87. De A, Boyadjieva N, Oomizu S, et al. Ethanol induces hyperprolactinemia by increasing prolactin release and lactotrope growth in female rats. Alcohol Clin.Exp.Res. 2002; 26:1420-1429. [PubMed: 12351938]

88. De A, Boyadjieva N, Pastorcic M, et al. Potentiation of the mitogenic effect of estrogen on the pituitary-gland by alcohol-consumption. Int.J Oncol. 1995; 7:643-648. [PubMed: 21552885]

89. Costa-e, Sousa RH.; Hollenberg, AN. Minireview: The neural regulation of the hypothalamicpituitary-thyroid axis. Endocrinology. 2012; 153:4128-35. [PubMed: 22759379]

90. Hegedus L, Rasmussen N, Ravn V, et al. Independent effects of liver disease and chronic alcoholism on thyroid function and size: the possibility of a toxic effect of alcohol on the thyroid gland. Metabolism. 1988; 37:229-233. [PubMed: 3343931]

91. Pienaar WP, Roberts MC, Emsley RA, et al. The thyrotropin releasing hormone stimulation test in alcoholism. Alcohol Alcohol. 1995; 30:661-667. [PubMed: 8554651]

92. Liappas I, Piperi C, Malitas PN, et al. Interrelationship of hepatic function, thyroid activity and mood status in alcohol-dependent individuals. In Vivo. 2006; 20:293-300. [PubMed: 16634533] 
93. Mason GA, Stanley DA, Walker $\mathrm{CH}$, et al. Chronic alcohol ingestion decreases pituitary-thyroid axis measures in Fischer-344 rats. Alcohol Clin.Exp.Res. 1988; 12:731-734. [PubMed: 3146228]

94. Zoeller RT, Fletcher DL, Simonyl A, et al. Chronic ethanol treatment reduces the responsiveness of the hypothalamic-pituitary-thyroid axis to central stimulation. Alcohol Clin.Exp.Res. 1996; 20:954-960. [PubMed: 8865974]

95. Baumgartner A, Eravci M, Pinna G, et al. Thyroid hormone metabolism in the rat brain in an animal model of 'behavioral dependence' on ethanol. Neurosci.Lett. 1997; 227:25-28. [PubMed: 9178850]

96. Moller N, Jorgensen JO. Effects of growth hormone on glucose, lipid, and protein metabolism in human subjects. Endocr.Rev. 2009; 30:152-177. [PubMed: 19240267]

97. Valimaki M, Tuominen JA, Huhtaniemi I, et al. The pulsatile secretion of gonadotropins and growth hormone, and the biological activity of luteinizing hormone in men acutely intoxicated with ethanol. Alcohol Clin.Exp.Res. 1990; 14:928-931. [PubMed: 2128439]

98. Valimaki M, Pelkonen R, Karonen SL, et al. Effect of ethanol on serum concentrations of somatomedin $\mathrm{C}$ and the growth hormone $(\mathrm{GH})$ secretion stimulated by the releasing hormone (GHRH). Alcohol Alcohol Suppl. 1987; 1:557-559. [PubMed: 3122774]

99. Valimaki M, Harkonen M, Ylikahri R. Acute effects of alcohol on female sex hormones. Alcohol Clin.Exp.Res. 1983; 7:289-293. [PubMed: 6414328]

100. Sonntag WE, Boyd RL. Chronic ethanol feeding inhibits plasma levels of insulin-like growth factor-1. Life Sci. 1988; 43:1325-1330. [PubMed: 3172983]

101. Soszynski PA, Frohman LA. Inhibitory effects of ethanol on the growth hormone (GH)-releasing hormone-GH-insulin-like growth factor-I axis in the rat. Endocrinology. 1992; 131:2603-2608. [PubMed: 1359962]

102. Soszynski PA, Frohman LA. Interaction of ethanol with signal transduction mechanisms mediating growth hormone release by rat pituitary cells in vitro. Endocrinology. 1992; 131:173180. [PubMed: 1351838]

103. Fernandez-Sola J, Preedy VR, Lang CH, et al. Molecular and cellular events in alcohol-induced muscle disease. Alcohol Clin.Exp.Res. 2007; 31:1953-1962. [PubMed: 18034690]

104. Lang CH, Fan J, Lipton BP, et al. Modulation of the insulin-like growth factor system by chronic alcohol feeding. Alcohol Clin.Exp.Res. 1998; 22:823-829. [PubMed: 9660307]

105. Ko CH, Takahashi JS. Molecular components of the mammalian circadian clock. Hum.Mol.Genet. 2006; 15:R271-R277. Spec No 2. [PubMed: 16987893]

106. Sarkar DK. Circadian genes, the stress axis, and alcoholism. Alcohol Res. 2012; 34:362-366. [PubMed: 23134053]

107. Perreau-Lenz S, Zghoul T, Spanagel R. Clock genes running amok. Clock genes and their role in drug addiction and depression. EMBO Rep. 2007; 8:S20-S23. Spec No. [PubMed: 17726437]

108. Chen CP, Kuhn P, Advis JP, et al. Chronic ethanol consumption impairs the circadian rhythm of pro-opiomelanocortin and period genes mRNA expression in the hypothalamus of the male rat. $\mathrm{J}$ Neurochem. 2004; 88:1547-1554. [PubMed: 15009656]

109. Jimenez V, Cardinali DP, Cano P, et al. Effect of ethanol on 24-hour hormonal changes in peripubertal male rats. Alcohol. 2004; 34:127-132. [PubMed: 15902906]

110. Brady KT, Sonne SC. The role of stress in alcohol use, alcoholism treatment, and relapse. Alcohol Res.Health. 1999; 23:263-271. [PubMed: 10890823]

111. Young ME. Anticipating anticipation: pursuing identification of cardiomyocyte circadian clock function. J Appl.Physiol. 2009; 107:1339-1347. [PubMed: 19608929]

112. Blomeyer D, Buchmann AF, Lascorz J, et al. Association of PER2 Genotype and Stressful Life Events with Alcohol Drinking in Young Adults. PLoS.One. 2013; 8:e59136. [PubMed: 23533602]

113. Wang X, Mozhui K, Li Z, et al. A promoter polymorphism in the Per3 gene is associated with alcohol and stress response. Transl.Psychiatry. 2012; 2:e73. [PubMed: 22832735]

114. Spanagel R, Pendyala G, Abarca C, et al. The clock gene Per2 influences the glutamatergic system and modulates alcohol consumption. Nat.Med. 2005; 11:35-42. [PubMed: 15608650] 
115. Logan RW, Sarkar DK. Circadian nature of immune function. Mol Cell Endocrinol. 2012; 349:82-90. [PubMed: 21784128]

116. Logan RW, Zhang C, Murugan S, O'Connell S, Levitt D, Rosenwasser AM, Sarkar DK. Chronic shift-lag alters the circadian clock of NK cells and promotes lung cancer growth in rats. $\mathrm{J}$ Immunol. 2012; 188(6):2583-91. [PubMed: 22308312]

117. Hodge AM, Dowse GK, Collins VR, et al. Abnormal glucose tolerance and alcohol consumption in three populations at high risk of non-insulin-dependent diabetes mellitus. Am.J Epidemiol. 1993; 137:178-189. [PubMed: 8452122]

118. Conigrave KM, Hu BF, Camargo CA Jr. et al. A prospective study of drinking patterns in relation to risk of type 2 diabetes among men. Diabetes. 2001; 50:2390-2395. [PubMed: 11574424]

119. Koppes LL, Dekker JM, Hendriks HF, et al. Moderate alcohol consumption lowers the risk of type 2 diabetes: a meta-analysis of prospective observational studies. Diabetes Care. 2005; 28:719-725. [PubMed: 15735217]

120. Avogaro A, Watanabe RM, Dall' Arche A, et al. Acute alcohol consumption improves insulin action without affecting insulin secretion in type 2 diabetic subjects. Diabetes Care. 2004; 27:1369-1374. [PubMed: 15161790]

121. Bonnet F, Disse E, Laville M, et al. Moderate alcohol consumption is associated with improved insulin sensitivity, reduced basal insulin secretion rate and lower fasting glucagon concentration in healthy women. Diabetologia. 2012; 55:3228-3237. [PubMed: 22935962]

122. Bantle AE, Thomas W, Bantle JP. Metabolic effects of alcohol in the form of wine in persons with type 2 diabetes mellitus. Metabolism. 2008; 57:241-245. [PubMed: 18191055]

123. Wei M, Gibbons LW, Mitchell TL, et al. Alcohol intake and incidence of type 2 diabetes in men. Diabetes Care. 2000; 23:18-22. [PubMed: 10857962]

124. Patto RJ, Russo EK, Borges DR, et al. The enteroinsular axis and endocrine pancreatic function in chronic alcohol consumers: evidence for early beta-cell hypofunction. Mt.Sinai J Med. 1993; 60:317-320. [PubMed: 8232378]

125. Kim JY, Song EH, Lee HJ, et al. Chronic ethanol consumption-induced pancreatic \{beta\}-cell dysfunction and apoptosis through glucokinase nitration and its down-regulation. J Biol Chem. 2010; 285:37251-37262. [PubMed: 20855893]

126. Dembele K, Nguyen KH, Hernandez TA, et al. Effects of ethanol on pancreatic beta-cell death: interaction with glucose and fatty acids. Cell Biol Toxicol. 2009; 25:141-152. [PubMed: 18330713]

127. Barnes PJ. How corticosteroids control inflammation: Quintiles Prize Lecture 2005. Br.J Pharmacol. 2006; 148:245-254. [PubMed: 16604091]

128. Urbach-Ross D, Kusnecov AW. Impact of superantigenic molecules on central nervous system function. Front Biosci. 2009; 14:4416-4426.

129. Wang HJ, Zakhari S, Jung MK. Alcohol, inflammation, and gut-liver-brain interactions in tissue damage and disease development. World J Gastroenterol. 2010; 16:1304-1313. [PubMed: 20238396]

130. Haorah J, Ramirez SH, Floreani N, et al. Mechanism of alcohol-induced oxidative stress and neuronal injury. Free Radic.Biol Med. 2008; 45:1542-1550. [PubMed: 18845238]

131. De A, Boyadjieva NI, Pastorcic M, et al. Cyclic AMP and ethanol interact to control apoptosis and differentiation in hypothalamic beta-endorphin neurons. J Biol Chem. 1994; 269:2669726705. [PubMed: 7929402]

132. Crews FT, Nixon K. Mechanisms of neurodegeneration and regeneration in alcoholism. Alcohol Alcohol. 2009; 44:115-127. [PubMed: 18940959]

133. Pfefferbaum A, Sullivan EV, Mathalon DH, et al. Frontal lobe volume loss observed with magnetic resonance imaging in older chronic alcoholics. Alcohol Clin.Exp.Res. 1997; 21:521529. [PubMed: 9161613]

134. Mochizuki H, Masaki T, Matsushita S, et al. Cognitive impairment and diffuse white matter atrophy in alcoholics. Clin.Neurophysiol. 2005; 116:223-228. [PubMed: 15589200]

135. Hellemans KG, Sliwowska JH, Verma P, et al. Prenatal alcohol exposure: fetal programming and later life vulnerability to stress, depression and anxiety disorders. Neurosci.Biobehav.Rev. 2010; 34:791-807. [PubMed: 19545588] 
136. Sarkar DK, Kuhn P, Marano J, et al. Alcohol exposure during the developmental period induces beta-endorphin neuronal death and causes alteration in the opioid control of stress axis function. Endocrinology. 2007; 148:2828-2834. [PubMed: 17347308]

137. Boyadjieva NI, Sarkar DK. Role of microglia in ethanol's apoptotic action on hypothalamic neuronal cells in primary cultures. Alcohol Clin.Exp.Res. 2010; 34:1835-1842. [PubMed: 20662807]

138. Crews FT, Mdzinarishvili A, Kim D, et al. Neurogenesis in adolescent brain is potently inhibited by ethanol. Neuroscience. 2006; 137:437-445. [PubMed: 16289890]

139. Fernandez-Lizarbe S, Pascual M, Guerri C. Critical role of TLR4 response in the activation of microglia induced by ethanol. J Immunol. 2009; 183:4733-4744. [PubMed: 19752239]

140. Zhang P, Bagby GJ, Happel KI, et al. Alcohol abuse, immunosuppression, and pulmonary infection. Curr.Drug Abuse Rev. 2008; 1:56-67. [PubMed: 19630706]

141. Stoltz DA, Zhang P, Nelson S, et al. Ethanol suppression of the functional state of polymorphonuclear leukocytes obtained from uninfected and simian immunodeficiency virus infected rhesus macaques. Alcohol Clin.Exp.Res. 1999; 23:878-884. [PubMed: 10371409]

142. Morland H, Johnsen J, Bjorneboe A, et al. Reduced IgG Fc-receptor-mediated phagocytosis in human monocytes isolated from alcoholics. Alcohol Clin.Exp.Res. 1988; 12:755-759. [PubMed: 2975475]

143. Lau AH, Szabo G, Thomson AW. Antigen-presenting cells under the influence of alcohol. Trends Immunol. 2009; 30:13-22. [PubMed: 19059005]

144. Arjona A, Boyadjieva N, Sarkar DK. Circadian rhythms of granzyme B, perforin, IFN-gamma, and NK cell cytolytic activity in the spleen: effects of chronic ethanol. J Immunol. 2004; 172(5): 2811-7. [PubMed: 14978081]

145. Boyadjieva NI, Chaturvedi K, Poplawski MM, Sarkar DK. Opioid antagonist naltrexone disrupts feedback interaction between mu and delta opioid receptors in splenocytes to prevent alcohol inhibition of NK cell function. J Immunol. 2004; 173:42-9. [PubMed: 15210757]

146. Pruett SB, Schwab C, Zheng Q, et al. Suppression of innate immunity by acute ethanol administration: a global perspective and a new mechanism beginning with inhibition of signaling through TLR3. J Immunol. 2004; 173:2715-2724. [PubMed: 15294990]

147. Mandrekar P, Bala S, Catalano D, et al. The opposite effects of acute and chronic alcohol on lipopolysaccharide-induced inflammation are linked to IRAK-M in human monocytes. J Immunol. 2009; 183:1320-1327. [PubMed: 19561104]

148. Nagy LE. Stabilization of tumor necrosis factor-alpha mRNA in macrophages in response to chronic ethanol exposure. Alcohol. 2004; 33:229-233. [PubMed: 15596091]

149. Boe DM, Nelson S, Zhang P, et al. Alcohol-induced suppression of lung chemokine production and the host defense response to Streptococcus pneumoniae. Alcohol Clin.Exp.Res. 2003; 27:1838-1845. [PubMed: 14634502]

150. Zisman DA, Strieter RM, Kunkel SL, et al. Ethanol feeding impairs innate immunity and alters the expression of Th1- and Th2-phenotype cytokines in murine Klebsiella pneumonia. Alcohol Clin.Exp.Res. 1998; 22:621-627. [PubMed: 9622442]

151. Sarkar DK, Murugan S, Zhang C, et al. Regulation of cancer progression by $\beta$-endorphin neuron. Cancer Res. 2012; 72:836-840. [PubMed: 22287549] 


\section{KEY POINTS}

- Chronic consumption of a large amount of alcohol disrupts the communication between nervous, endocrine and immune system and causes hormonal disturbances that lead to profound and serious consequences at physiological and behavioral levels.

- These alcohol-induced hormonal dysregulations affect the entire body and can result in various disorders such as stress abnormalities, reproductive deficits, body growth defect, thyroid problems, immune dysfunction, cancers, bone disease and psychological and behavioral disorders. 


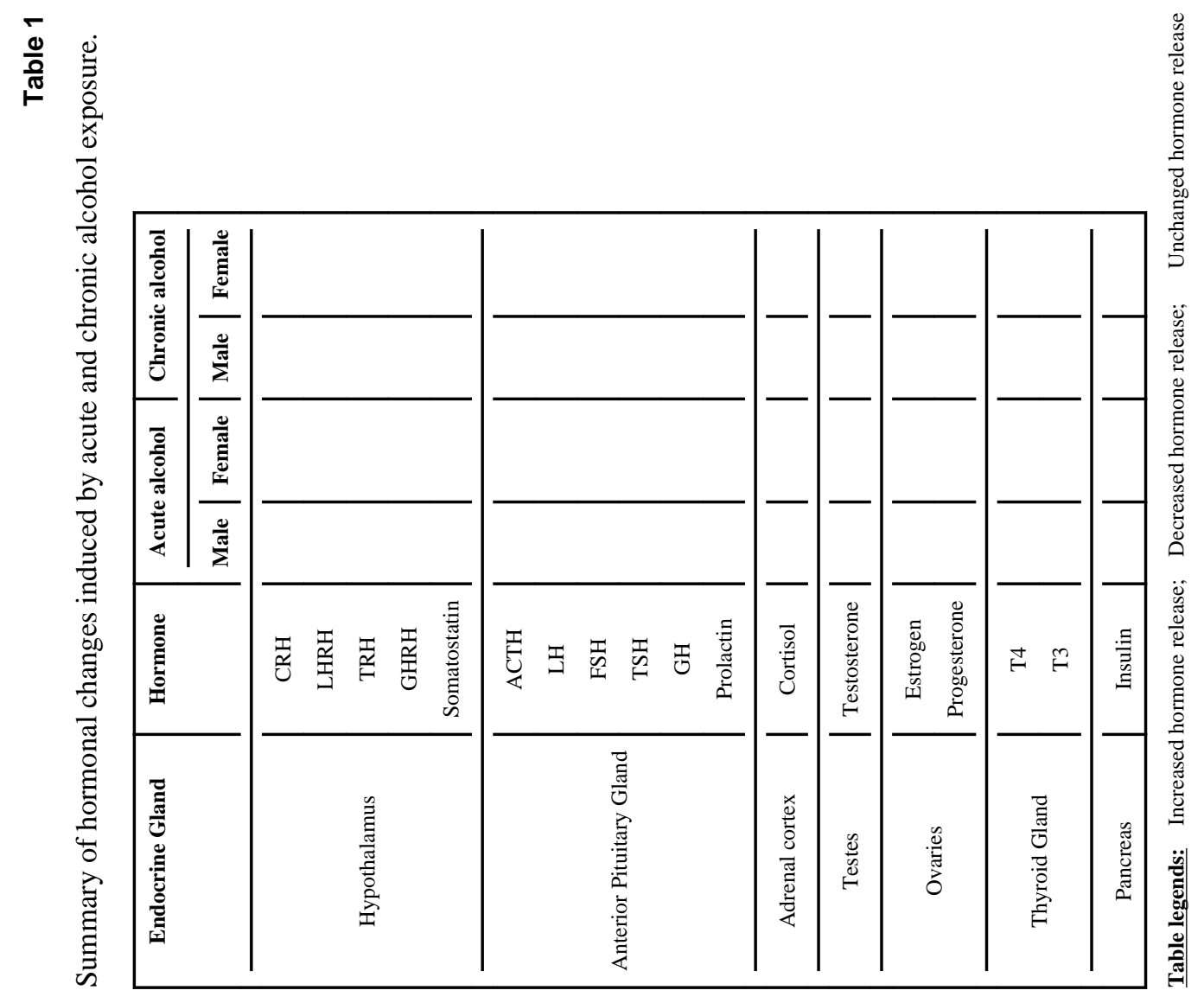

Endocrinol Metab Clin North Am. Author manuscript; available in PMC 2014 September 01. 